Elsevier required licence: (c) <2019>.

This manuscript version is made available under the CC-BY-NC-ND 4.0 license

http://creativecommons.org/licenses/by-nc-nd/4.0/

The definitive publisher version is available online at

https://www.sciencedirect.com/science/article/pii/S0921344919302861?via\%3Dihub 


\title{
Using the waste Kuznet's curve to explore regional variation in the decoupling of waste generation and socioeconomic indicators
}

\author{
Ben Madden ${ }^{\mathrm{a}, *}$, Nick Florin ${ }^{\mathrm{a}}$, Steve Mohr $^{\mathrm{a}}$, Damien Giurco ${ }^{\mathrm{a}}$ \\ ${ }^{a}$ Institute for Sustainable Futures, University of Technology Sydney, Ultimo NSW Australia
}

\begin{abstract}
Decoupling of resource consumption from economic growth is a key principle in the transition towards a circular economy. This study explores regional variation in the decoupling of waste generation from mean income in the Australian state of New South Wales (NSW), following the Waste Kuznet's Curve (WKC) hypothesis. The WKC hypothesis tests for the existence of a relationship between waste and economic indicators conforming to an inverted-U shape that may indicate decoupling. A geographically and temporally weighted regression (GTWR) model is used to test the WKC hypothesis for municipal waste from 2011 to 2015. We identify municipalities conforming to the WKC hypothesis, and examine the socioeconomic and urban morphological characteristics of these municipalities. Results show that waste policy must be targeted to consider local variability in socioeconomics. Municipalities across rural NSW were found to conform to the WKC over the time frame. WKC-conforming municipalities had higher per-capita rates of waste generation, and lower mean incomes compared to non-conforming municipalities. Ratios of tipping point (global maximum) to mean income for WKC conforming municipalities were estimated between 0.8 to 2 , indicating that these municipalities are in stages of relative, rather than absolute, decoupling. This study demonstrates the application of the WKC for examining decoupling, and highlights the importance of considering variations in regional characteristics when assessing the decoupling of waste generation from income. Findings also broadly suggest regionally specific policy making is required for circular economy transitions in NSW.
\end{abstract}

Keywords: Kuznets curve, Municipal solid waste, Decoupling, Geographically and temporally weighted regression

\section{Introduction}

Historically when populations and economies grow, the amount of waste generated as a result of consumption and economic activity generally also increases. This presents a significant future challenge for the

${ }^{*}$ Corresponding author

Email address: benjamin.madden@uts.edu.au (Ben Madden)

Preprint submitted to Resources, Conservation \& Recycling

June 18, 2019 
sustainable management of wastes. The circular economy concept is one response to unsustainable levels of consumption, waste generation, and their associated environmental impacts that has received much attention in recent years Kirchherr et al. (2017). In the context of sustainable waste management, the circular economy maintains the value of end-of-life materials and products in the economy for as long as possible by avoiding disposal. This is done through better product design and manufacturing, reuse, remanufacturing, and recycling, thereby minimising waste generation along the entire supply chain Ellen MacArthur Foundation, 2015). This has important implications for waste management systems, which must provide the waste infrastructure and collection systems to enable the transition to the circular economy.

A recognised key step in the transition towards the circular economy is the decoupling of resource consumption from economic growth (Suárez-Eiroa et al., 2019, Ellen MacArthur Foundation, 2015). Decoupling can generally be defined as either 'relative' or 'absolute' decoupling, and can occur at different levels of the economy. Relative decoupling sees economic growth occur at a faster pace than resource consumption, implying a gain in efficiency rather than a total delinking of economic performance and environmental impact (Ward et al. 2016). On the other hand, absolute decoupling sees a decrease in resource use despite increasing economic performance. Absolute decoupling can be an indication that environmental pressure is stable or falling, and is therefore an essential concept for sustainable economic growth (Montevecchi, 2016; Jackson, 2009 ).

Global economy wide data on domestic material consumption has implied that a relative, and in some cases absolute, decoupling has been achieved in a number of countries (OECD, 2018). However, findings in Wiedmann et al. (2016) indicate that when non-domestic sources of resource consumption such as imported consumer goods are taken into account, no level of decoupling, relative or absolute, has been achieved globally. Whilst the viability of simultaneously pursuing economic growth and reduced environmental impacts remains contested (Fletcher \& Rammelt, 2017, Ward et al., 2016), achieving an absolute decoupling of waste generation from economic growth is also an important objective to strive for, in light of increasing volumes and environmental impacts of waste generated annually that must be dealt with sustainably Mazzanti \& Nicolli, 2012).

Where a decoupling between waste and economic performance exists, waste generation might follow an inverted-U shape relationship against economic indicators (Montevecchi, 2016, Ichinose et al., 2011). The economist Simon Kuznets first hypothesised this relationship between income levels and economic inequality which increases with income until reaching a 'tipping point' from where it begins to decrease (Kuznets, 1955). This 'Kuznets curve' relationship has since been applied in the form of the environmental Kuznets curve (EKC) to model decoupling behaviour between environmental impact and economic growth. In this context, Mazzanti \& Zoboli (2009) and Ichinose et al. (2011) define absolute decoupling as the descending part of the inverted-U shape, and relative decoupling as the ascending part of the inverted-U shape. Ichinose et al. (2011) furthers these definitions by defining absolute decoupling to occur only when the tipping point from 
the estimated Kuznets curve is within the range of the economic indicator for the area under investigation, and relative decoupling where the estimated tipping point occurs outside this range. Such decoupling like behaviour may indicate an economy shifting away from manufacturing towards a more de-materialised, service based economy where environmental degradation might decrease (Ercolano et al., 2018), owing to reduced pressure on the environment.

Recently, the EKC has been applied to examine solid waste generation (Ercolano et al., 2018, Jaligot \& Chenal, 2018; Kim et al. 2018; Mazzanti et al., 2008). Despite the causal links between economic growth and waste generation, there is a lack of consensus on the existence of the 'waste Kuznets curve' (WKC). This demonstrates a need for further research on the application of the WKC for identifying decoupling like behaviour. Ercolano et al. (2018) identifies that studies that do support the WKC hypothesis are primarily at sub-national scales, which compared to cross-country analyses, allow for consideration of within country/region heterogeneity in waste generation and other driving factors. Analyses performed at a spatially disaggregated level require spatially explicit data, such as waste generation data for local government areas. Such data however often shows robust patterns of spatial dependency where for example nearby locations share similar attributes and influence each other, requiring spatiality to be a feature of analysis (Montello \& Sutton, 2012, Goodchild, 1992).

This paper explores regional variation in decoupling of municipal waste and mean income following the WKC hypothesis. A geographically and temporally weighted regression model (GTWR) is developed to explore this variation across municipalities in the Australian state of New South Wales (NSW), where a circular economy agenda has recently been put in place (NSW Government, 2018). This paper uses annual municipal per-capita waste generation data for local government areas (LGAs) in NSW for the years 2011 to 2015, in addition to relevant socioeconomic, demographic, and urban morphology variables derived from census data. The primary goal of this study is to identify local government areas (LGAs) within NSW that conform to the WKC hypothesis, and to examine locally varying determinants of per-capita waste generation in NSW. This study gives insights into the application of the WKC for assessing the status of decoupling between per-capita waste generation and mean income. We apply this approach to NSW for the first time, and the findings from this study may have important implications supporting regionally appropriate and targeted policy development towards more circular economy practices.

\section{Background}

\subsection{The WKC hypothesis}

There is a lack of consensus on the existence of the WKC in the literature. Mazzanti et al. (2008) reviews studies undertaken from 1995 to 2007 to examine the existence of the WKC. Of the 13 studies reviewed in Mazzanti et al. (2008), 5 studies found evidence supporting the existence of the WKC. Berrens et al. 
(1998) and Wang et al. (1998) found evidence of the WKC in studies undertaken across the United States, examining hazardous waste data across 3,141 counties. Concu (2000) found evidence of the WKC in their study in Sardinia, Italy for municipal waste generation. Fischer-Kowalski \& Amann (2001) found evidence of the WKC across OECD countries, but for landfilled waste only, and not waste generation. Ercolano et al. (2018) identifies that the studies that do support the WKC hypothesis are primarily at the sub-national level, which better allows for the consideration of within country/region heterogeneity in waste generation and other factors due to the disaggregated nature of sub-national data (e.g., municipalities, counties, etc.). Sub-national level studies are much rarer in the literature compared to cross country analyses, where crosscountry studies show little evidence supporting the WKC hypothesis (Ercolano et al., 2018). Recent research into the existence of the EKC and WKC has also examined regional effects at the sub-national level. Kim et al. (2018) employs a geographically weighted regression (GWR) approach to examine regional specific industrial pollutants ( $\mathrm{SO}_{2}$ emissions, wastewater discharge, and solid waste generation) across 29 provinces in China. The authors find significant spatial variation in the existence of the EKC, with spatial patterns identified through the GWR attributed to regional policy making. Jaligot \& Chenal (2018) use a panel regression model on waste generation data across 10 districts in the Swiss canton of Vaud, using tax point value (income) as an economic development proxy. Findings from Jaligot \& Chenal (2018) indicate the existence of the WKC, and the trend emerges more strongly when additional socioeconomic factors are incorporated into the authors' model. Mazzanti et al. (2008) perform a regression analysis on municipal waste generation data from municipalities in northern and southern Italy, using provincial value added per capita as an economic performance proxy, finding evidence of a WKC that varies across the regions investigated.

This study builds on the existing literature by applying GTWR in the context of decoupling waste generation from economic performance to a region where the WKC hypothesis has yet to be examined. Owing to the lack of consensus in previous studies to the existence of the WKC, there is value in examining the relationship in a new region, and such analysis might provide further evidence for or against its existence.

\subsection{Study area}

The study area is the Australian state of New South Wales, consisting of 128 local government areas (see Figure 1). The local government areas of NSW all operate independent waste management systems, with kerbside collection being the main form of municipal waste collection across the state. For this study, the 'Unincorporated Far West Region' was excluded, as this area is not part of a local government area and is administered federally.

The study area has a total population as of the 2016 census of 7,608,010. The vast majority of the population is located on the east coast around population centres such as the Sydney Metropolitan area, where approximately $60 \%$ of the total state's population resides in an area less than $1 \%$ of the total state's 


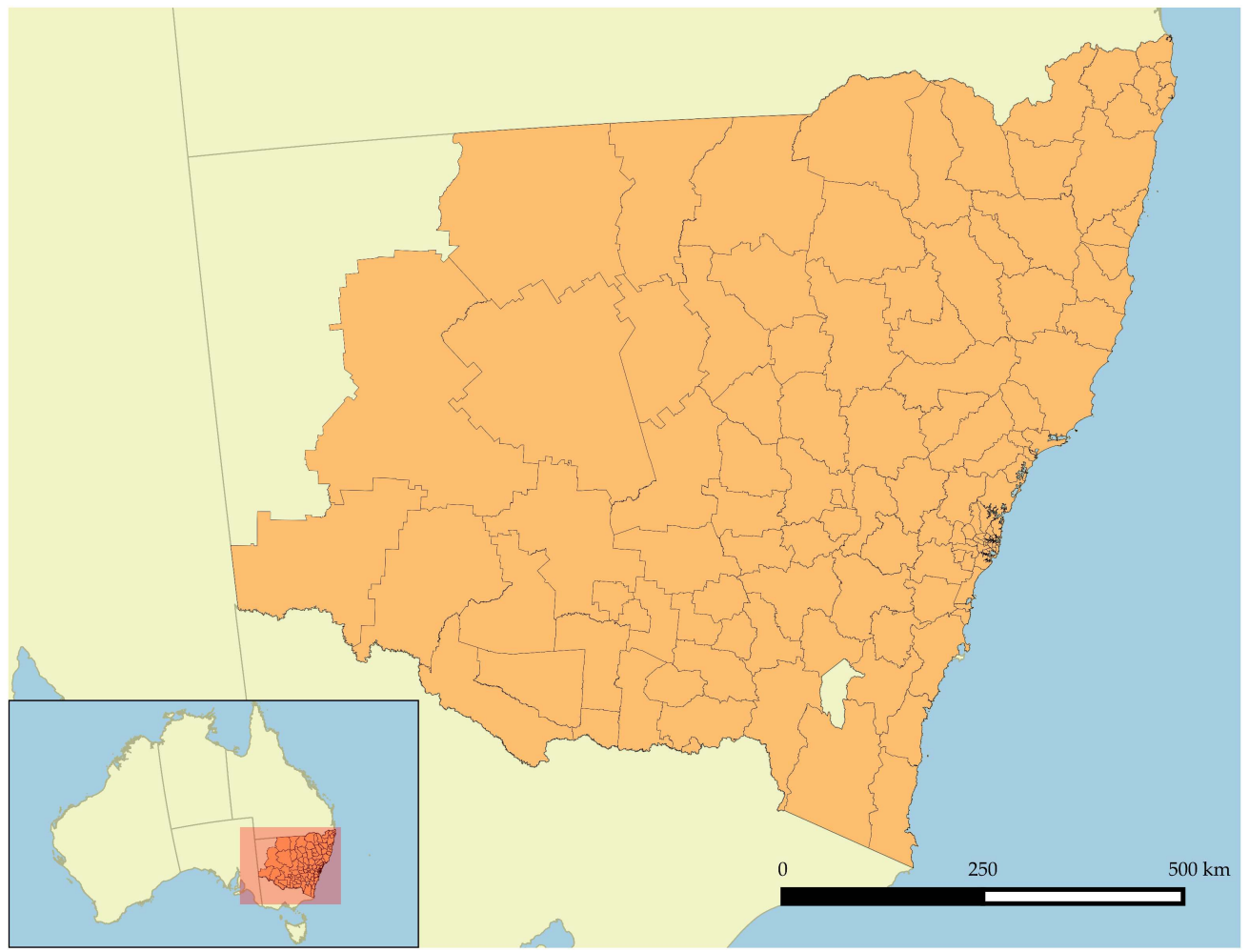

Figure 1: Map showing the New South Wales study area highlighted, and the local government area boundaries

land area.

The recent Chinese National Sword policy limiting waste imports into China (World Trade Organization, 2017) has led to focused attention for regions in transitioning towards circular economic practices. The NSW Circular Economy Statement (NSW Government, 2018) specifically references decoupling economic growth from resource consumption as a core principle in the state's circular economy transition. In this context, this research provides new information to support policy development by identifying areas of the state where material decoupling may be taking place, which may lead to more appropriately targetted policies in the transition to the circular economy, and could also be important for measuring progress in transitioning towards a circular economy.

\subsection{Data}

The dataset used includes data on 128 local government areas over the timeframe 2011 to 2015 . Waste data were gathered from the NSW Environment Protection Authority annual Waste Avoidance and Resource Recovery reports, describing each local government area's municipal waste generation for a given reporting year. The most recent published waste data for NSW is the 2014/15 financial year (NSW EPA, 2016). Figure 2 shows the distribution of municipal waste generation across the dataset. Average rates of per-capita generation are relatively consistent across the study timeframe. The proportion of recycling collected to total 
waste collected per local government area was also collected, and used as a proxy for the performance of an area's waste management system under the assumption that high rates of recycling collection infers a goodperforming waste management system. Figure 3 shows the spatial distribution of average waste generated per capita across the study area and study timeframe, showing that there is some spatial heterogeneity in the average rates of MSW generated per capita.

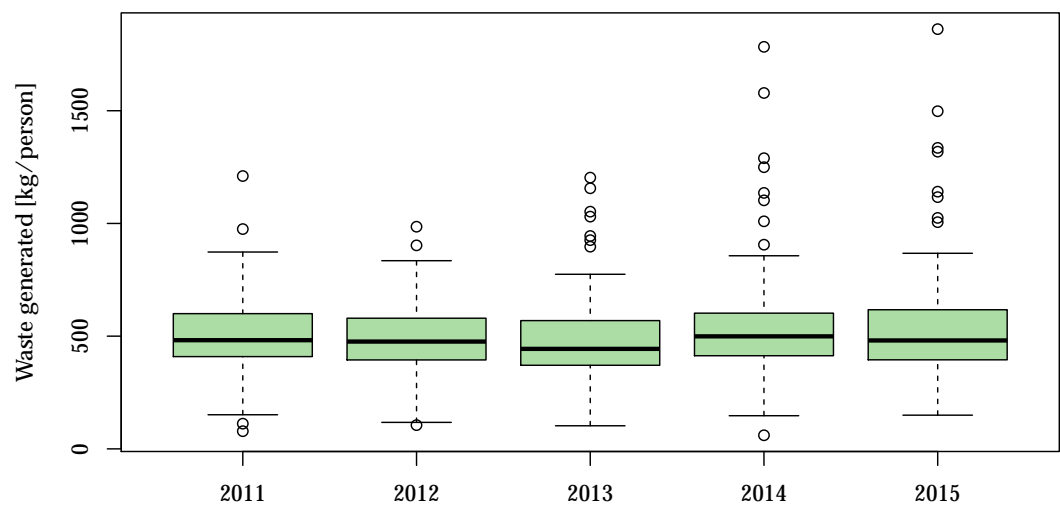

Figure 2: Distribution of MSW generated per capita, 2011-2015

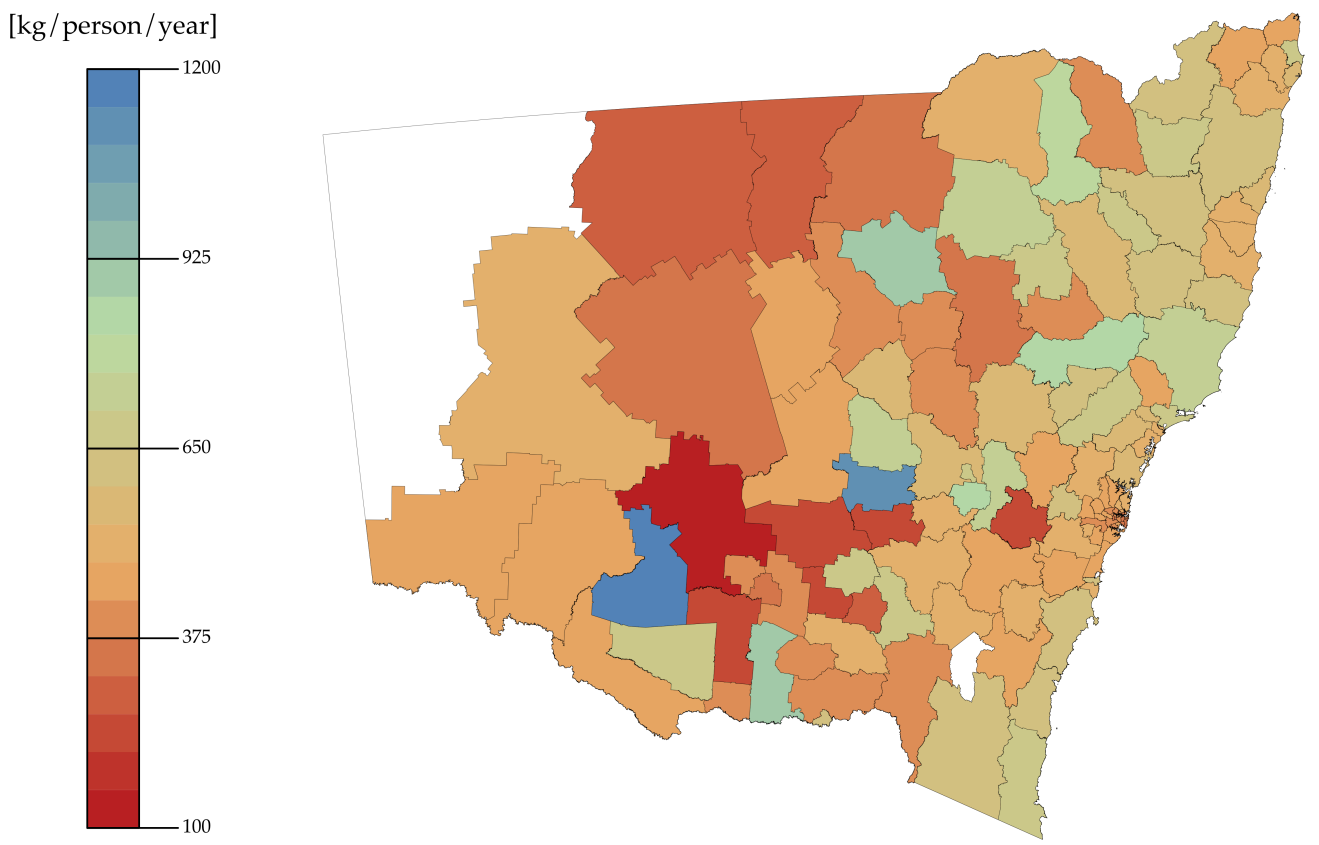

Figure 3: Spatial distribution of average per-capita MSW generation for 2011-2015 over the study area

Spatial data was gathered from the Australian Bureau of Statistics, which provides local government area boundaries. It is important to note that from 2015 some NSW local government areas were merged to form new, larger local government areas. Socioeconomic and demographic data collected for the 2016 
Australian census is aligned to these new government boundaries. In order to align the datasets, waste data were aggregated from pre-merged council areas to the new local government boundaries using GIS and published weighting factors (Australian Bureau of Statistics, 2016).

Demographic and socioeconomic data were collected from yearly data published by local government area across NSW (Australian Bureau of Statistics, 2018). This data spans from the 2011 Australian census to 2017. Only the 2011 to 2015 demographic and socioeconomic data were used to align with available waste data. Initial variables selected for this study were subject to availability and model selection, as data is not available for all socioeconomic and demographic factors that appear in each census conducted in 5-yearly intervals. Variables for analysis in this study are those that are published by the Australian Bureau of Statistics based on yearly intervals only (Australian Bureau of Statistics, 2018), and include population, number of households, household occupancy, income, and population density. Tourism, which is noted as being a driver for waste generation (Oribe-Garcia et al. 2015), was not available over the timeframe or at a municipal level therefore was excluded from our analysis.

The WKC hypothesis relates to economic growth and development, and an appropriate proxy for economic development must be selected. To the best of the authors' knowledge, there are no published data on local government areas' gross regional product (GRP) in the study timeframe, therefore other proxies for economic growth and development must be considered. Many studies in the literature have indicated the positive correlation between income and/or wealth with waste generation (Kannangara et al., 2018, Sun \& Chungpaibulpatana, 2017; Trang et al., 2017; Khan et al., 2016, Oribe-Garcia et al., 2015, Keser et al. 2012; Dyson \& Chang, 2005)). Ercolano et al. (2018) and Jaligot \& Chenal (2018), Mazzanti et al. (2008) use the average tax return per person, tax point value (income), and value added per person respectively for economic development proxies. Kim et al. (2018), testing both the EKC and WKC hypotheses, uses GRP per capita as a proxy. For this study, we use the mean annual household income measure.

Final variables to be used in the GTWR model were selected based on minimising multicollinearity between candidate independent variables, as GWR and GTWR models can be sensitive to multicollinearity. For this, the variance inflation factor (VIF) was calculated iteratively for each independent variable $k \in K$ (Belsley et al. 1980) (Equation 1):

$$
\mathrm{VIF}_{k}=1 /\left(1-R_{k}^{2}\right)
$$

The VIF is calculated by forming a regression model with the independent variable $k$ acting as the dependent variable, regressed against the other potential independent variables. Variable screening is done by iteratively calculating the VIF for each independent variable, and removing potential variables from $K$ whose VIF exceeds a cut-off threshold. For this study, the cut-off threshold was chosen as $1 /\left(1-R^{2}\right)$, where $R^{2}$ is the coefficient of determination of the full regression model with $K$ independent variables. Descriptive statistics of the final selected variables are tabulated in Table 1 


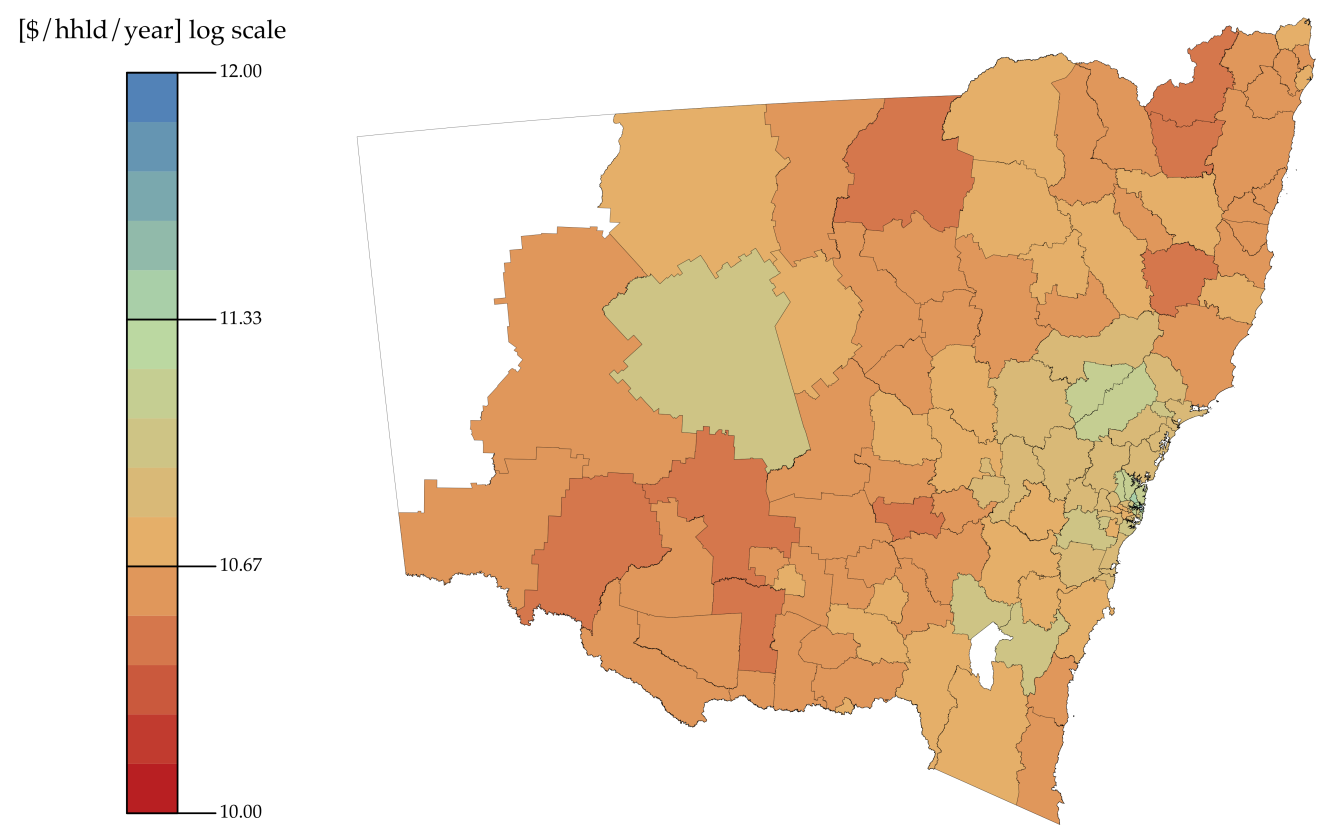

Figure 4: Spatial distribution of mean income, 2011-2015

Table 1: Descriptive statistics of the variables used in this study

\begin{tabular}{lllll}
\hline Variable & Mean & Minimum & Maximum & SD \\
\hline Per-capita waste generation [PCG] (kg/pers) & 510.7 & 60.4 & $1,862.1$ & 206.2 \\
Mean income [INC] (\$) & $50,111.22$ & 32,312 & 134,180 & $14,479.31$ \\
Pop. density [POP.DENS] (pers/km²) & 731.5 & 0.04 & $8,055.3$ & $1,582.8$ \\
Households [HHLDS] (num) & 22960.1 & 749 & 143,549 & 27,764 \\
Household size [HHLD.SIZE] (pers/hh) & 2.3 & 1.4 & 3.7 & 0.4 \\
Proportion recycling [PROP.REC] (dmnl) & 0.38 & 0 & 0.73 & 0.2 \\
Distance to urban [DIST.URBAN] (km) & 44.77 & 0 & 396.59 & 66.71 \\
\hline
\end{tabular}




\section{Method}

\subsection{Overview of method}

We examine the existence of the WKC in NSW by first establishing a functional relationship between waste generation and selected socioeconomic and urban morphological variables. A number of different functional relationships have been utilised in the literature for testing the Kuznets curve relationship, most often using a regression based approach (Ercolano et al., 2018; Jaligot \& Chenal, 2018, Kim et al., 2018, Mazzanti et al., 2008; Maddison, 2006). The general functional relationship for testing this hypothesis is in Equation 2.

$$
Y=\beta_{0}+\beta_{1} X_{1}+\beta_{2} X_{1}^{2}+\beta_{k} X_{k}+\epsilon
$$

where $Y$ is the waste generation variable, $\epsilon$ is the error term, $\beta_{i}$ are regression coefficients to be estimated, $X_{1}$ is the economic development proxy variable, and $X_{k}$ are other variables used to establish the relationship between waste generation and other socioeconomic drivers. Equation 2 is quadratic, which implies the dependent variable in Equation 2 tends to $\pm \infty$ as the independent variable(s) increases. Some studies such as Jaligot \& Chenal (2018) use higher order polynomial functions in addition to the quadratic form to model more complex relationships (i.e., an N-shaped curve, where rebound occurs after decoupling) between the environmental variable and economic performance. For this study, we focus on the quadratic form of the WKC relationship as expressed in Equation 2 due to the short timeframe of this study, where more complex behaviour may have yet to emerge. The WKC hypothesis can thus be tested by comparing the $\beta_{1}$ and $\beta_{2}$ coefficients as per the relationships presented in Table 2 .

Table 2: WKC hypothesis framework

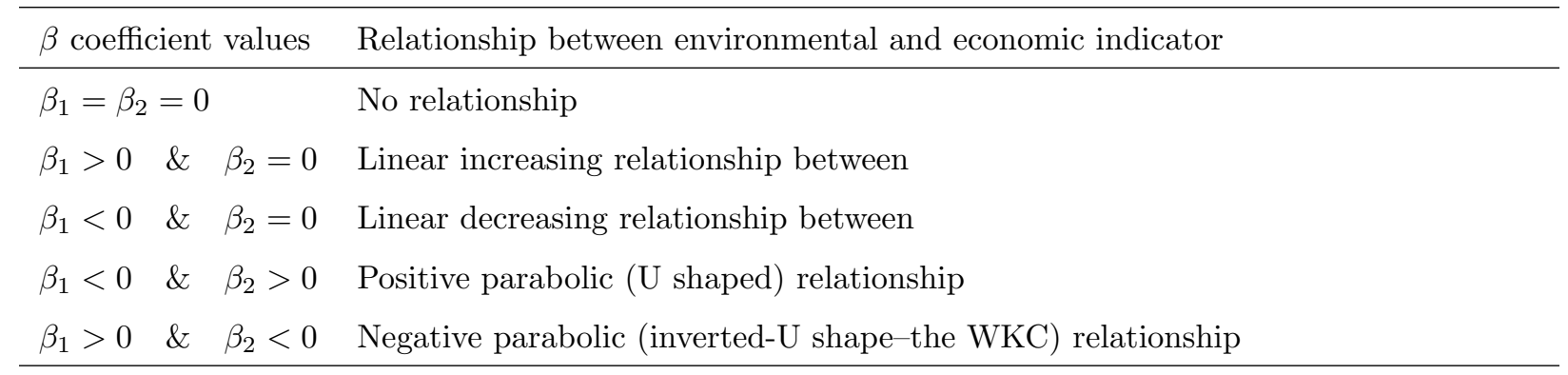

The relationships in Table 2 can be confirmed in Equation 2 if the $\beta_{1}$ and $\beta_{2}$ coefficients are found to be statistically significant. Moreover, $\beta_{1}$ must be positive to ensure a positive tipping point can be estimated from the model.

We use municipal waste generation per-capita and mean income as the waste and economic indicators respectively for our study. Other variables used and their selection are discussed previously. The functional relationship is examined firstly by using pooled OLS regression across NSW by pooling all LGAs, with the 
WKC hypothesis being validated as per the framework presented in Table 2, This 'global' model (global in the sense that a single model relates to the entire study space) gives a baseline of statewide WKC conformity, and estimates a tipping point in annual mean income terms for all of NSW, used to compare with results from further regional analysis using GTWR. The global model is also used to assess spatial autocorrelation of the pooled OLS residuals, to ascertain the level of spatial association in the data. Assessing spatial autocorrelation, and evaluating the fit of the pooled OLS model provides further justification for the use of a spatial model (i.e., the GTWR model) to determine regional WKC conformity across NSW. The results of the GTWR model are analysed to identify the LGAs that conform with the WKC hypothesis for each year of the study, and to estimate individual tipping points for WKC conforming LGAs.

\subsection{Geographically and temporally weighted regression (GTWR)}

To analyse regional variation in the existence of the WKC, GTWR is used. GTWR is an extention of geographically weighted regression, with the addition of temporal non-stationarity being taken into account. GWR/GTWR are examples of spatially varying coefficient models, which extend OLS regression such that regression parameters can vary over space and are estimated locally (Du et al., 2018, Ma et al., 2018, Keser et al. 2012, Huang et al. 2010). Before describing GTWR, GWR is first introduced. A GWR model can be expressed as follows in Equation 3

$$
Y_{i}=\beta_{0}\left(u_{i}, v_{i}\right)+\sum_{k} \beta_{k}\left(u_{i}, v_{i}\right) X_{i k}+\epsilon_{i} \quad i=1, \ldots, N
$$

where $N$ is the number of locations, $\left(u_{i}, v_{i}\right)$ are the coordinates of a regression point $i$ (for this study, the geometric centroid of a local government area) in space, $\beta_{0}\left(u_{i}, v_{i}\right)$ is the intercept at location $i$, and $\beta_{k}\left(u_{i}, v_{i}\right)$ is the estimated coefficient of the $k$ th variable $X_{k}$ at location $i$.

A limitation of GWR is that temporal nonstationarity is not considered. GTWR extends the GWR framework by considering temporal, in addition to spatial, non-stationarity by constructing an appropriate spatiotemporal weighting matrix to measure the distance between regression locations in both space and time. The GTWR model is presented in Equation 4.

$$
Y_{i}=\beta_{0}\left(u_{i}, v_{i}, t_{i}\right)+\sum_{k} \beta_{k}\left(u_{i}, v_{i}, t_{i}\right) X_{i k}+\epsilon_{i} \quad i=1, \ldots, N
$$

For parameter estimation, it is assumed that observed data near the $i$ th point would have a greater influence in the estimation of the $\beta_{k}\left(u_{i}, v_{i}, t_{i}\right)$ parameters than data located further away in space and time from location $i$ (Huang et al. 2010). Parameter estimation for $\beta_{k}\left(u_{i}, v_{i}, t_{i}\right)$ is given by Equation 5

$$
\beta\left(u_{i}, v_{i}, t_{i}\right)=\left[\mathbf{X}^{T} \mathbf{W}\left(u_{i}, v_{i}, t_{i}\right) \mathbf{X}\right]^{-1} \mathbf{X}^{T} \mathbf{W}\left(u_{i}, v_{i}, t_{i}\right) \mathbf{Y}
$$

where $\mathbf{W}\left(u_{i}, v_{i}, t_{i}\right)$ is an $n \times n$ matrix of spatiotemporal weights relative to the position of $\left(u_{i}, v_{i}, t_{i}\right), \mathbf{X}$ is the vector of independent variables, and $\mathbf{Y}$ is the vector of dependent variable values. The weight matrix 
$\mathbf{W}\left(u_{i}, v_{i}, t_{i}\right)$ has zeros in its off-diagonal elements, and the spatiotemporal weighting of observation data for observation $i$ in its diagonal elements (Huang et al., 2010):

$$
\mathbf{W}\left(u_{i}, v_{i}, t_{i}\right)=\operatorname{diag}\left\{W_{i 1}, W_{i 2}, \ldots, W_{i n}\right\}
$$

The weighting matrix refers to the relative importance of each individual observation across the data set based on Tobler's law, where nearer observations to $i$ have greater influence on parameter estimation than observations further from $i$ (Lewandowska-Gwarda, 2018). GTWR extends this by also considering that observations closer in time to $i$ are also more influential than observations occuring further in the past.

Deriving the weighting matrix is through either a fixed or adaptive kernel based weight function. For the adaptive kernel, distance is constant but the number of nearest neighbours to location $i$ varies (Huang et al. 2010). For fixed, this case is reversed where the number of nearest neighbours is fixed, but distance varies.

Typically, two potential kernels are used as weighting functions-Gaussian based functions, and the bisquare weighting function, although a wide range of other distance decay functions can be utilised (for example, the exponential function). For this study, the fixed bisquare kernel is used as it offered the greatest model fit, and is described as follows in Equation 7

$$
W_{i j}= \begin{cases}{\left[1-\left(\frac{d_{i j}^{S T}}{h}\right)^{2}\right]} & \text { if } d_{i j}^{S T}<h \\ 0 & \text { otherwise }\end{cases}
$$

where $h$ is the bandwidth or distance threshold, and $d_{i j}^{S T}$ is the spacetime distance between observations $i$ and $j$.

Estimating $h$ regardless of the weighting regime chosen is done through optimisation against a goodness of fit statistic, such as cross-validation or the corrected Aikaike Information Criterion (AICc). Minimising the AICc provides greater accuracy for small sample sizes according to Kim et al. (2018), and is defined as follows in Equation 8

$$
\mathrm{AIC}_{\mathrm{c}}=2 n \ln \left(\hat{\sigma}^{2}\right)+n \ln (2 \pi)+n\left(\frac{n+\operatorname{tr}(S)}{n-2-\operatorname{tr}(S)}\right)
$$

where $\hat{\sigma}^{2}$ is the estimated standard deviation of the error term, and $\operatorname{tr}(S)$ is the trace of the hat matrix which maps the vector of dependent variable values to the vector of fitted values.

Estimating spatiotemporal distance $d^{S T}$ is difficult due to distance and time being measured in different units (here, meters and years) and therefore have different scale effects (Huang et al., 2010). Given a spatial distance $d^{S}$ and a temporal distance $d^{T}$, spatiotemporal distance $d^{S T}$ can be calculated such that Huang et al. 2010):

$$
d^{S T}=d^{S} \otimes d^{T}
$$


where $\otimes$ represents some operator. Du et al. (2018), Ma et al. (2018) and Huang et al. (2010) define $\otimes$ as a simple linear combination of spatial and temporal distance, with scale parameters $\lambda$ and $\mu$ to balance the different scale effects (e.g., if $d^{S}$ is much larger than $d^{T}$, then spatial distance will dominate $d^{S T}$, and vice-versa (Wu et al. 2014)):

$$
d^{S T}=\lambda d^{S}+\mu d^{T}
$$

For this study, we use the GWmodel (Gollini et al. 2015) implementation of GTWR in the $R$ statistical computing language to estimate the GTWR model, which implements an improved GTWR model based on (Wu et al. 2014). Here, a more complex $\otimes$ operator is utilised to control the interaction of space and time effects, and to ensure that only previous 'time neighbours' (i.e., observations occurring in the past) (Wu et al., 2014) are taken into consideration:

$$
\begin{cases}d_{i j}^{S T}=d_{i j}^{S} \otimes d_{i j}^{T}=\lambda d_{i j}^{S}+\mu d_{i j}^{T}+2 \sqrt{\lambda \mu d_{i j}^{S} d_{i j}^{T}} \cos (\xi) & t_{j}<t_{i} \\ d_{i j}^{S T}=\infty & t_{j}>t_{i}\end{cases}
$$

where $\lambda$ and $\mu$ are adjustment parameters between 0 and 1 to scale the different scale effects (with $\mu=1-\lambda$ as implemented by $G W$ model). $\xi$ is a parameter introduced by Wu et al. (2014) to control the interaction of space and time effects, and is between 0 and $\pi$. Selection of the $\lambda$ and $\xi$ parameters is done through optimisation of a goodness-of-fit statistic.

\section{Results \& discussion}

The final functional relationship for this study is expressed as:

$$
\begin{aligned}
& \widehat{P C G}_{i t}=\beta_{0}+\beta_{1} \log I N C_{i t}+\beta_{2} \log I N C_{i t}^{2}+\beta_{3} P C G_{i, t-1} \\
& +\beta_{4} \log \text { POP.DENS } i t+\beta_{5} H H L D S_{i t}+\beta_{6} \text { PROP.REC } C_{i t} \\
& +\beta_{7} \log \text { DIST.URBAN } N_{i} \beta_{8} H H L D . S I Z E_{i t}+\epsilon
\end{aligned}
$$

where $P C G$ is per-capita municipal waste generation. A lagged per-capita waste generation term $\left(P C G_{t-1}\right)$ is included under the expectation that historical waste generation would influence waste management decision making, and thus be a determinant of future waste generation. INC is mean household income, POP.DENS is population density, HHLDS is the number of households, HHLD.SIZE is the size (occupancy) of households, PROP.REC is the proportion of municipal waste collected as recycling, and DIST.URBAN is the minimum distance from the geometric centroid of an LGA to the nearest significant urban area Australian Bureau of Statistics, 2017). INC, POP.DENS and DIST.URBAN variables have been log transformed to account for skew in the data. 


\subsection{Global model results}

The global model serves as a baseline to compare the results of the estimated GTWR model to be discussed in the following section, and expresses the relationship between the independent and dependent variables for the entire state of NSW without consideration for spatial effects. Table 3 presents the results of the global model across the pooled LGA data.

Table 3: Global regression model results

\begin{tabular}{lrrrr}
\hline Variable & $\beta$ Estimate & $\mathrm{SE}$ & $t$ value & $p$-value \\
\hline Intercept & $-43,440$ & 13,040 & -3.332 & $<0.000$ \\
$\log I N C$ & 8,024 & 2,379 & 3.373 & $<0.000$ \\
$\log I N C^{2}$ & -365.3 & 108.3 & -3.374 & $<0.000$ \\
PCG & 0.6538 & 0.0509 & 12.852 & $<0.000$ \\
$\log$ POP.DENS & -6.78 & 6.656 & -1.019 & 0.309 \\
HHLDS & -0.0001 & 0.0004 & -0.238 & 0.812 \\
PROP.REC & 171.7 & 53.75 & 3.194 & 0.001 \\
$\log$ DIST.URBAN & 1.239 & 3.893 & 0.318 & 0.750 \\
HHLD.SIZE & -0.602 & 31.10 & -1.936 & 0.053 \\
$R^{2}$ & & & & 0.2861 \\
AIC & & & & 6789.946 \\
$p-$ value & & & & $<0.000$ \\
\hline
\end{tabular}

Both mean income and its square are significant, with signs of each income term agreeing with the Kuznets curve hypothesis indicating that without consideration of LGA variation in the independent variables, there is a decoupling of waste generation and income over the state. In addition, $P C G_{t-1}$ and PROP.REC are also statistically significant. From these results, we can calculate the tipping point from the values of the $\beta$ coefficients for the two income terms $\left(\beta_{1}\right.$ and $\left.\beta_{2}\right)$ :

$$
\exp \left(-\beta_{1} /\left[2 \beta_{2}\right]\right)
$$

From Equation 13, the global tipping point is estimated as a mean income of AUD\$58,839 (AUD = Australian Dollar, where AUD $\$ 1=\mathrm{USD} \$ 0.69$, as of June 2019). It was found that 22 LGAs had mean incomes above the estimated tipping point over the study time period, with 17 of these LGAs located within the Sydney Metropolitan Area (SMA). This result is expected, considering that economic activity is much greater within the SMA and therefore higher mean incomes compared to regional LGAs is likely. Figure 5 the distribution of mean incomes and per-capita generation rates for LGAs, relative to the estimated tipping point. 


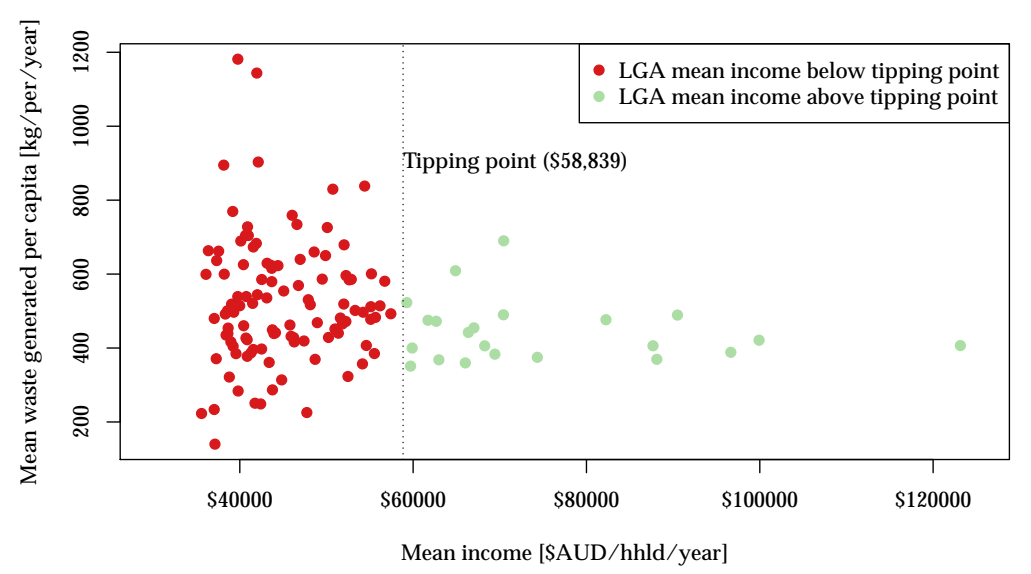

Figure 5: Average LGA mean incomes vs. Average LGA per-capita waste generation, compared to global model tipping point estimate

Overall model fit of the global pooled OLS model is poor, demonstrated by an adjusted- $R^{2}$ value of 0.286 , however such a fit is consistent with similar models in the waste management literature. Lebersorger \& Beigl (2011) for example note that in their review that coefficients of determination $\left(R^{2}\right)$ rarely exceed 0.5 for regression models estimating waste generation, however Oribe-Garcia et al. (2015) for example obtained $R^{2}$ values of between 0.279 and 0.980 for their regression models estimating waste generation in Biscay. Oribe-Garcia et al. (2015) cite several other similar studies (i.e., regression based models for estimating waste generation) in their paper, with $R^{2}$ values ranging from 0.51 to 0.88 .

We test for spatial autocorrelation of model residuals from the global model by calculating Moran's $I$, which is a measure of spatial autocorrelation taking values $[-1,1]$. A Moran's $I$ between 0 and 1 indicates a clustering of values, whereas a Moran's $I$ between -1 and 0 indicates regular distribution of values. A Moran's $I$ of $\approx 0$ indicates random distribution (i.e., no spatial association) of values being tested. Moran's $I$ can be calculated from the following (Bivand et al. 2008$)$ :

$$
I=\frac{n \sum_{i} \sum_{j \neq i} w_{i j}\left(Y_{i}-\bar{Y}\right)\left(Y_{j}-\bar{Y}\right)}{\left(\sum_{i} \sum_{j \neq i} w_{i j}\right) \sum_{i}\left(Y_{i}-\bar{Y}\right)^{2}}
$$

where $Y_{n}$ is the model residual for observation $n$ from the global model, $\bar{Y}$ is the mean model residual, and $w_{i j}$ is the $i, j$-th element of the $n \times n$ spatial proximity matrix $W$, which provides a distance weighting for each pair of observation points $i$ and $j$. Proximity is determined by the number of nearest neighbours to observation points $i$, which describes the maximum number of adjacent neighbours to $i$ from which distance is measured. Statistical significance of the Moran's I estimate is obtained by comparing the standard deviate of the Moran's I statistic with the normal distribution (Bivand et al. 2008).

The results from the Moran's $I$ analysis are presented in Table 4 indicating that spatial autocorrelation 
of residuals exists for all levels of nearest neighbours tested (2 to 10 nearest neighbours), and that model residuals for the global OLS model are more clustered than random. The value of the Moran's $I$ shows a decreasing trend as the number of nearest neighbours increase. This is expected as the distance between observation points increase as additional neighbours are considered (Goovaerts, 1997). This is consistent with findings from Keser et al. (2012) who identified a similar pattern of spatial autocorrelation of residuals in their GWR study modelling waste generation in Turkey. The importance of this finding is that there is a spatial association between the dependent and independent variables, indicating that explicitly controlling for spatiality (for example, through GWR/GTWR) is appropriate for this study.

Table 4: Results of Moran's I test for spatial autocorrelation of residuals from global OLS model

\begin{tabular}{lll}
\hline Num. nearest neighbours & Morans $I$ & $p$-value \\
\hline 2 & 0.5339 & $<0.000$ \\
3 & 0.5880 & $<0.000$ \\
4 & 0.6627 & $<0.000$ \\
5 & 0.6627 & $<0.000$ \\
6 & 0.4887 & $<0.000$ \\
7 & 0.3754 & $<0.000$ \\
8 & 0.2875 & $<0.000$ \\
9 & 0.2198 & $<0.000$ \\
10 & 0.2198 & $<0.000$ \\
\hline
\end{tabular}

\subsection{GTWR local model results}

The GTWR model uses the same functional relationship as the pooled OLS global model expressed in Equation 12, with estimated regression coefficients varying across LGAs, as per Equation $4 . \lambda$ and $\xi$ parameters were selected using a Monte-Carlo simulation approach with $\lambda$ and $\xi$ values sampled from a uniform distribution of candidate values $(\lambda \in[0,1] ; \xi \in[0, \pi])$. The GTWR model with the highest adjusted coefficient of determination was selected as the final model from 10,000 iterations. Figure 6 shows the results of these simulations. From these results, model fit is highly sensitive to variations in $\lambda$ above a certain threshold. Adjusted $R^{2}$ values increase monotonically with $\lambda$ until $\lambda \approx 0.6$, from which point adjusted $R^{2}$ values are erratic. For $\lambda<\approx 0.6$, values of $\xi$ appear to not have a significant impact on the model fit, indicating that there is little interaction between spatial and temporal effects for $\lambda<\approx 0.6$, and that coefficient estimates are more heavily weighted towards spatial effects than temporal for models with high $R^{2}$ values. Table 5 shows the selected parameter values for the final GTWR model. Appendix Appendix $\mathrm{A}$ shows $\beta$ coefficient estimates and $t$-values for the two mean income variables in the final GTWR model 


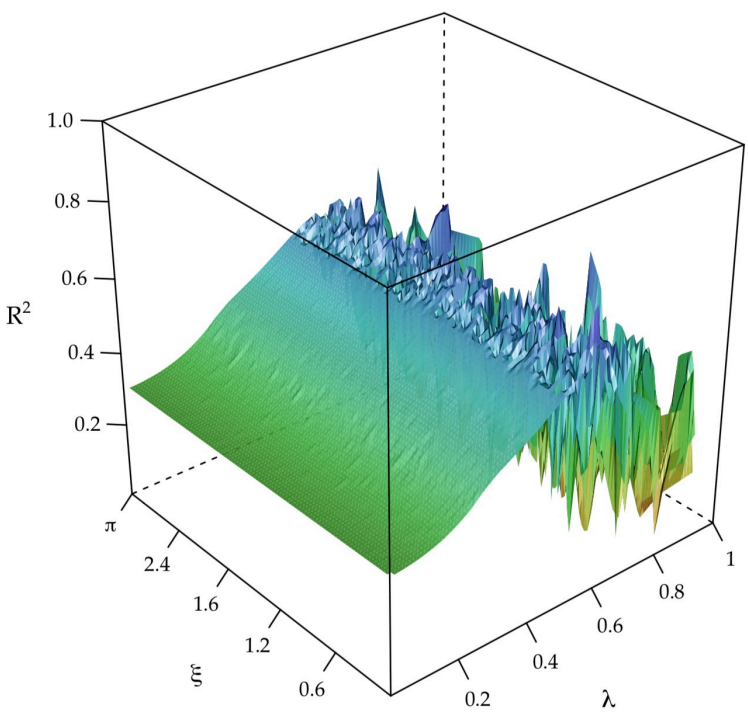

Figure 6: Results of Monte-Carlo simulation for selection of $\xi$ and $\lambda$ GTWR parameters

Table 5: Selected GTWR parameter values

\begin{tabular}{ll}
\hline Parameter & Value \\
\hline$\lambda$ & 0.61 \\
$\xi$ & 0.02 \\
\hline
\end{tabular}

Table 6 summarises coefficient estimates for all LGAs and years from the GTWR model, exhibiting variation over the study space. Comparing with results from the global model in Table 3, GTWR estimates fluctuate around those given from the global model, however variation is large indicating that the global model lacks the complexity given by considering spatiality.

Confirming the spatial and temporal nonstationarity of GTWR coefficient estimates further justifies the use of GTWR over the global OLS model (Ma et al. 2018). Ma et al. (2018) confirm the spatiotemporal nonstationarity of GTWR coefficient estimates following Fotheringham et al. (2015) and Fotheringham et al. (2002) by comparing the interquartile range from the GTWR estimates for each variable with twice the standard error of the pooled OLS model estimates for each variable. For this paper, we also examine the spatiotemporal heterogeneity of the GTWR estimates by comparing with the global pooled OLS estimates under the null hypothesis that coefficient estimates from the GTWR model are not significantly different from the pooled OLS estimates (i.e., spatiotemporal nonstationarity does not exist), using the nonparametric Wilcoxon signed-rank test. Results for both of these analyses are presented in Table 7. These results show 
Table 6: Results of the GTWR local model

\begin{tabular}{lrrrrr}
\hline Variable & Mean & Minimum & First Quartile & Third Quartile & Maximum \\
\hline Intercept & $-45,620.043$ & $-1.31 \mathrm{e}+06$ & $-32,232.804$ & 14.781 & $1.73 \mathrm{e}+06$ \\
$\log I N C$ & $8,142.385$ & $-328,968.73$ & 16.759 & 5,758 & $242,580.403$ \\
$\log I N C^{2}$ & -361.056 & $-11,196.324$ & -260.319 & 3.19 & $15,518.116$ \\
PCG & 0.6 & -1.228 & 0.517 & 0.693 & 1.546 \\
$\log$ POP.DENS & 44.497 & $-7,565.399$ & -38.774 & 36.681 & $8,122.298$ \\
HHLDS & -0.012 & -1.056 & -0.002 & 0.001 & 1.825 \\
PROP.REC & -18.666 & $-1,922.000$ & -125.812 & 135.705 & $1,509.057$ \\
$\log$ DIST.URB & 52.808 & $-9,907.817$ & -5.52 & 8.483 & $10,347.847$ \\
HHLD.SIZE & -60.038 & $-2,828.026$ & -158.458 & 33.241 & $3,314.306$ \\
\hline
\end{tabular}

that the coefficient estimates from the GTWR exhibit spatiotemporal nonstationarity, indicating that locally weighted GTWR coefficients significantly differ from those produced from the global pooled OLS model.

Table 7: Summary of spatial nonstationarity of GTWR coefficient estimates results

\begin{tabular}{lcccc}
\hline Variable & Interquartile (GTWR) & $2 \times \mathrm{SE}(\mathrm{OLS})$ & Wilcoxon test statistic & $p$-value \\
\hline Intercept & $32,247.58$ & $26,073.11$ & 0.49 & 0.000 \\
$\ln I N C$ & $5,742.17$ & $4,757.62$ & 0.50 & 0.000 \\
$\ln I N C^{2}$ & 263.51 & 216.54 & 0.51 & 0.000 \\
$P C G_{t-1}$ & 0.18 & 0.10 & 0.81 & 0.000 \\
$\ln P O P . D E N S$ & 77.45 & 13.31 & 0.21 & 0.000 \\
HHLDS & 0.00 & 0.00 & 0.22 & 0.000 \\
PROP.REC & 261.52 & 107.50 & 0.87 & 0.000 \\
$\ln$ DIST.URB & 14.00 & 7.79 & 0.16 & 0.000 \\
HHLD.SIZE & 191.70 & 62.19 & 0.63 & 0.000 \\
\hline
\end{tabular}

A benefit of GWR/GTWR as an exploratory tool is the possibility of mapping model coefficient estimates over space and time. Statistically significant GTWR model coefficients (with $p$-values $<0.05$ ) are presented as thematic maps in Figure 7. For Figure 7, the average coefficient values over time are used for visualisation following Ma et al. (2018), who suggests that mapping the eigenvalues of the coefficients (e.g., the average values) is useful for visualising spatial variation (Ma et al. 2018). Of note from these results is that significant income coefficients occur for a set of clustered LGAs, west of the Sydney metropolitan area. Further discussion is provided below. 
Other variables exhibit significant coefficients across a greater proportion of the state, most notably the lagged per-capita waste generation, number of households, household size, and population density variables (Figure 7). The analysis found that household size is a greater determinant of per-capita waste generation compared with the number of households, whose coefficient estimates across the study area are $\approx 0 . \mathrm{A}$ significant negative relationship is identified between per-capita waste generation and household size. This effect is most strongly associated with LGAs within the Murray and Southern Inland regions along the Victoria-NSW state border. Kolekar et al. (2016) cites in a review of predictive models that household size is often a significant determinant of waste generation. Kumar \& Samadder (2017) and Trang et al. (2017) find significant positive relationships between household size and waste generation. A negative relationship between these variables may indicate that as the number of household occupants increase, households become more efficient in using materials through for example sharing and re-use, resulting in a lower per-capita rate of waste generation.

Coefficient estimates for the proportion of waste collected as recycling was found to be quite clustered, with LGAs near more developed regions showing a positive relationship with per-capita waste generation. This relationship may be expected where improvements in waste management practices (e.g., increased separately collected recycling) are a response to increasing rates of waste generation, not as a measure to reduce waste generation through better waste disposal behaviour. Coefficient estimates for the lagged per-capita waste generation variable shows that across NSW, a mild increasing trend in per-capita waste generation is identified, indicated by coefficients $<1$.

Significant population density coefficients show a generally negative relationship with per-capita waste generation, which is mostly strongly associated with the Greater Sydney Metropolitan Area and its surrounds. A similar relationship between waste generation and population density was found in Oribe-Garcia et al. (2015). Such a relationship could indicate areas with a higher proportion of high-density residential development, where rates of per-capita generation are typically lower due to reduced green waste generated for example. Conversely, areas showing a positive relationship between population density and per-capita generation, may indicate LGAs with a lower level of urban development and waste infrastructure.

Model fit of the GTWR model is superior to that of the global OLS model, indicated by goodness-of-fit statistics reported in Table 8. The improvement of model fit by utilising GTWR is consistent with the literature, as Lewandowska-Gwarda (2018); Yu (2006) report. GWR/GTWR will usually produce better fitting models over global OLS models given that the spatial model better controls for spatial (and temporal, in the case of GTWR) hetereogeneity (Lewandowska-Gwarda, 2018).

\subsection{Empirical findings for the WKC hypothesis}

The existence of the WKC can be identified following the framework presented in Section 2.1. Figure 8 shows the LGAs where the WKC hypothesis is met across the time period analysed, and Figure 9 shows 


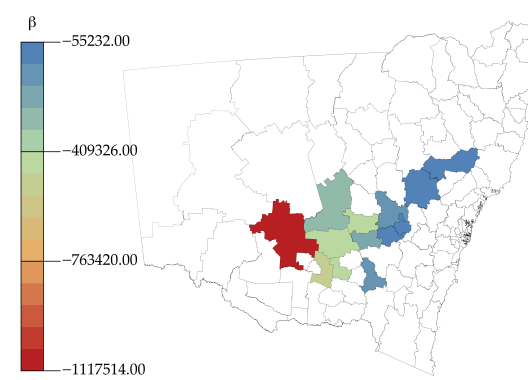

(a) Intercept
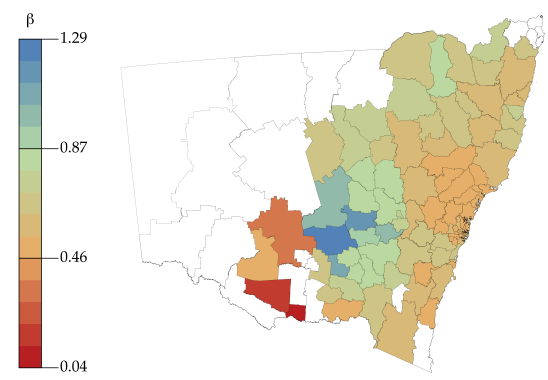

(d) Per cap. generation $(t-1)$
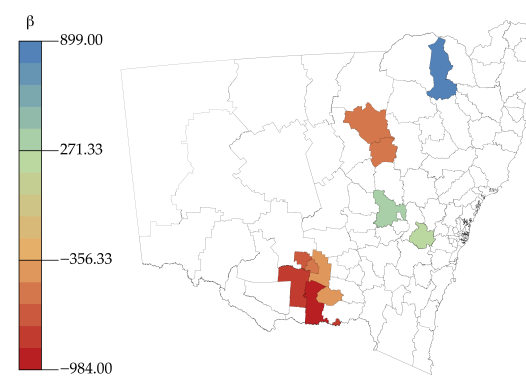

(g) Proportion recycling
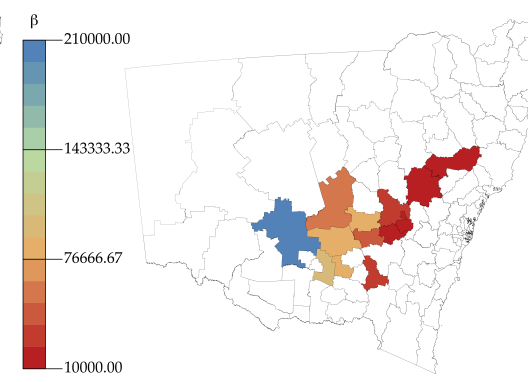

(b) $\log ($ Mean income)
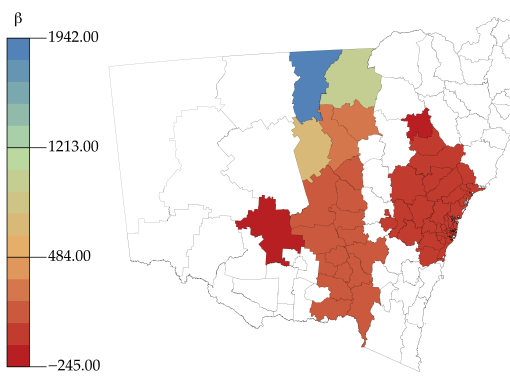

(e) $\log$ (Population density)
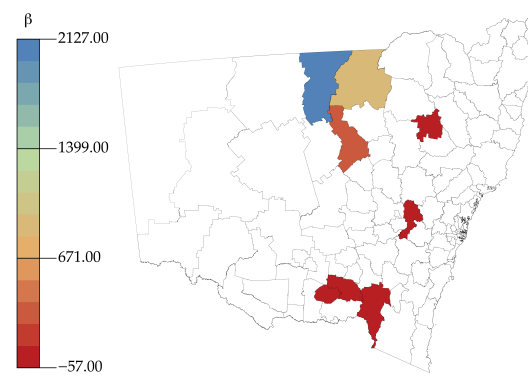

(h) $\log ($ Distance to urban)
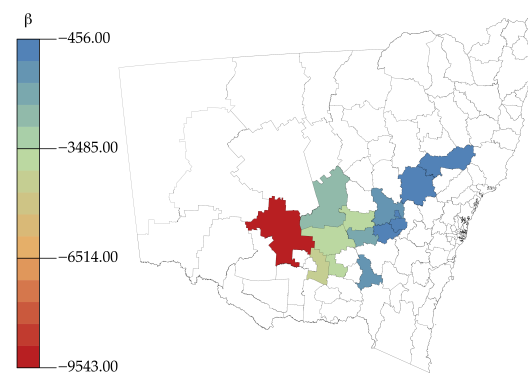

(c) $\log (\text { Mean income })^{2}$
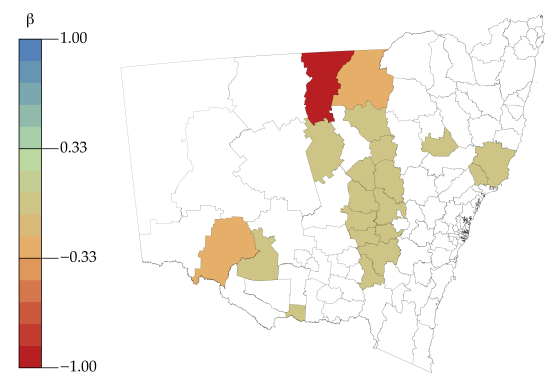

(f) Households
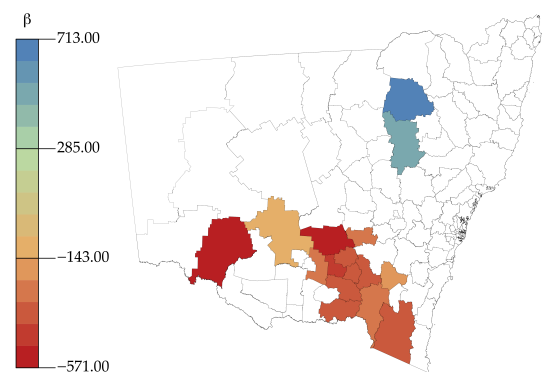

(i) Household size

Figure 7: Average coefficient estimates from GTWR model

Table 8: Goodness-of-fit statistics for local GTWR and global OLS models

\begin{tabular}{lcc}
\hline & Local GTWR model & Global OLS model \\
\hline$R^{2}$ & 0.699 & 0.297 \\
Adjusted $R^{2}$ & 0.611 & 0.286 \\
AIC & 6435.682 & 6789.946 \\
\hline
\end{tabular}




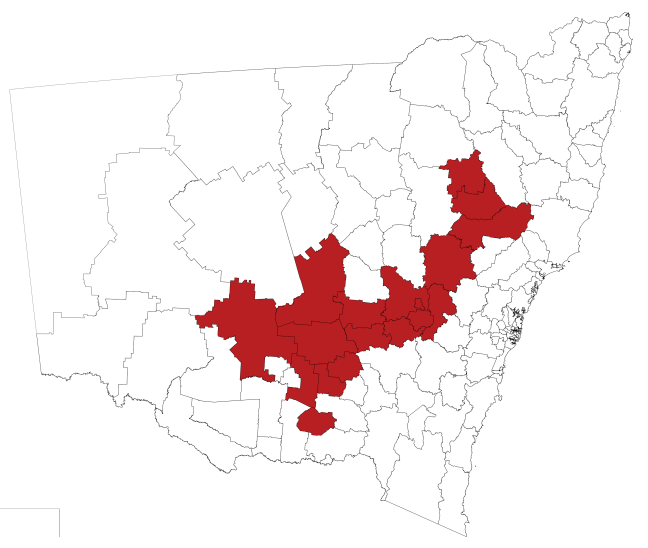

(a) 2012

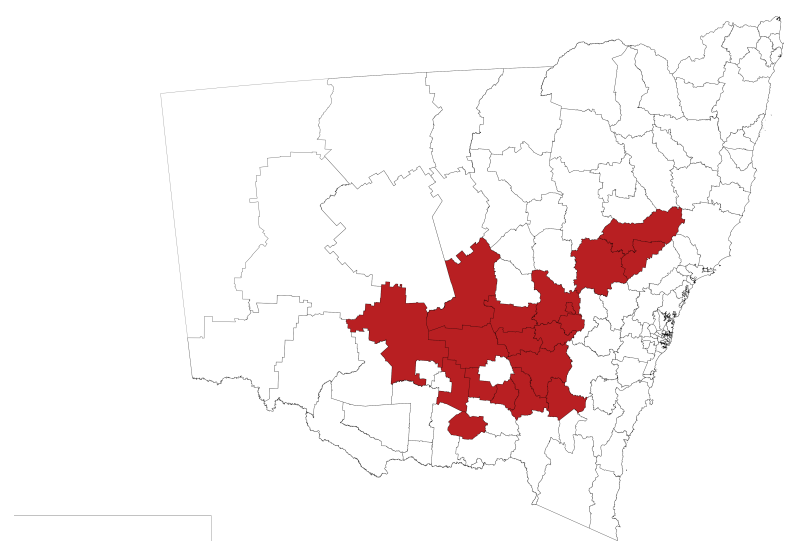

(c) 2014

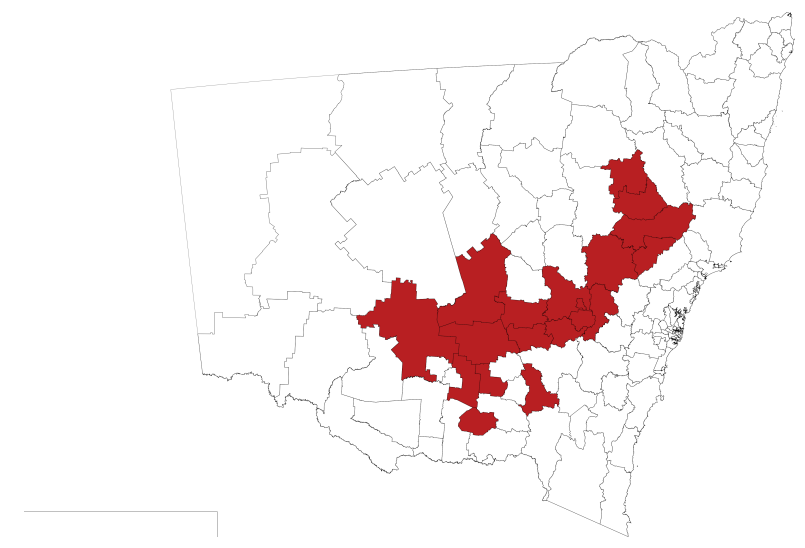

(b) 2013

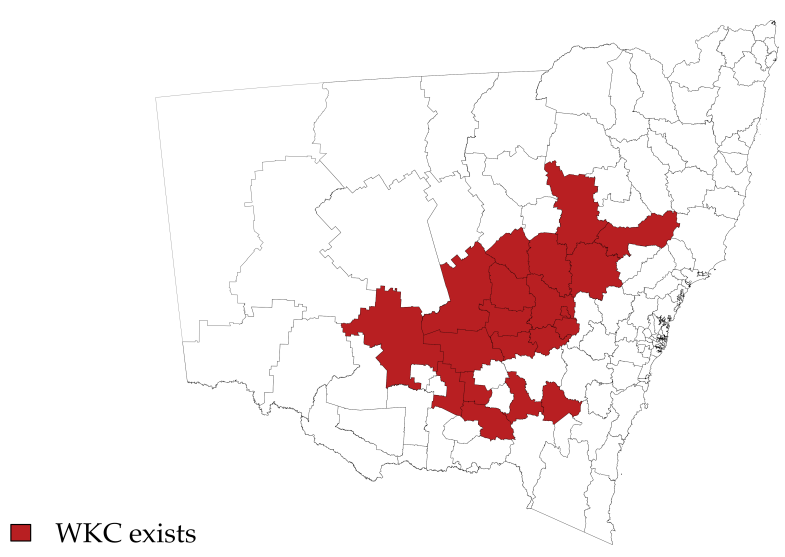

(d) 2015

Figure 8: Local government areas conforming to the WKC hypothesis

LGAs within NSW that exhibit the WKC are located across the Orana, Hunter, Central West, Murray, and Riverina regions directly west of the Sydney metropolitan area. The total number of LGAs conforming to the WKC hypothesis vary over the time frame, showing an increasing trend. Table 9 shows the number of LGAs conforming to the WKC for each year, including the proportion of WKC conforming LGAs to total state LGAs, proportion of the NSW population residing in WKC conforming LGAs, and average estimated tipping points for these LGAs.

Tipping point mean incomes have been estimated between approximately $\$ 48,000 /$ annum to $\$ 76,000 /$ annum. Average mean income across these LGAs in 2015 is approximately $\$ 47,400 /$ annum, compared to $\$ 54,400$ for all other LGAs. The ratio of tipping point to mean income ranges from 0.8 to 2 times local mean income for these LGAs (Figure 9p. These ratios are quite high for some LGAs, considering a lower level of economic development in regional NSW where the WKC conforming LGAs are located. High tipping 

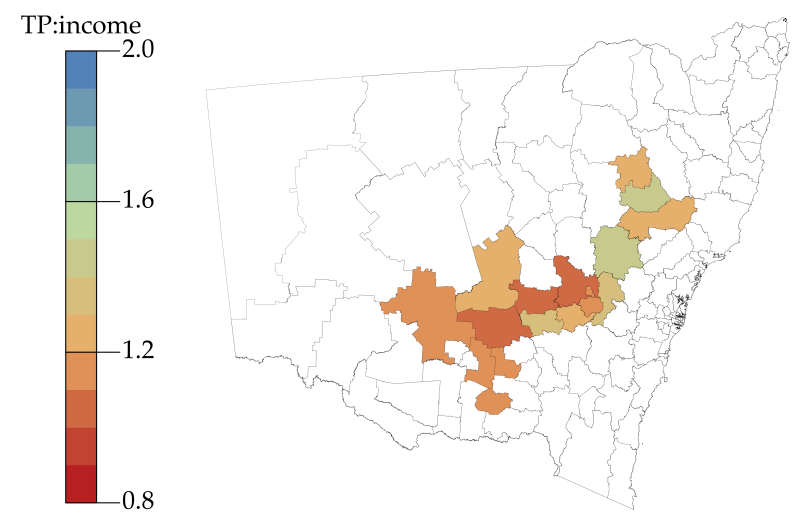

(a) 2012
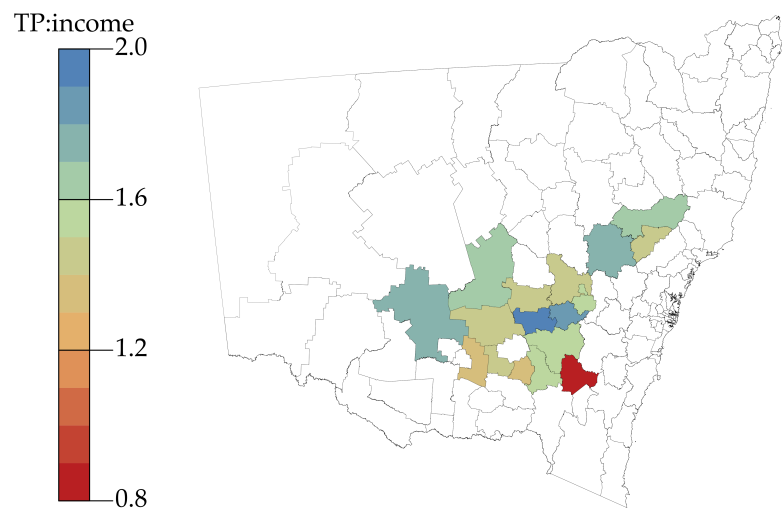

(c) 2014
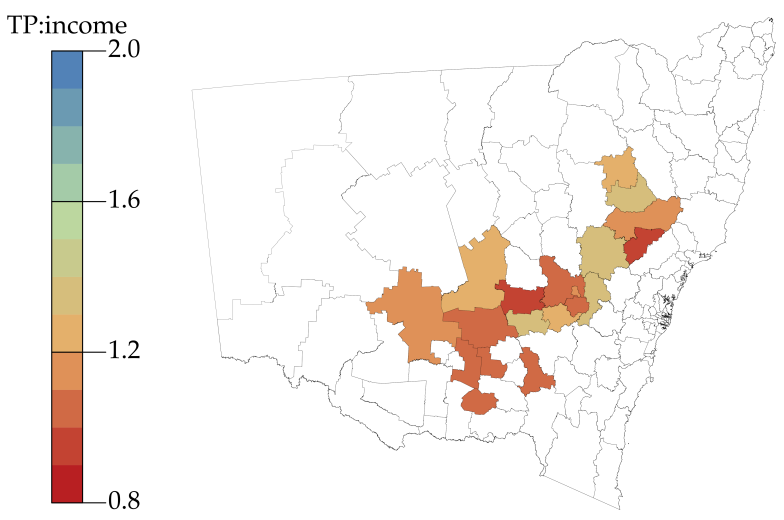

(b) 2013
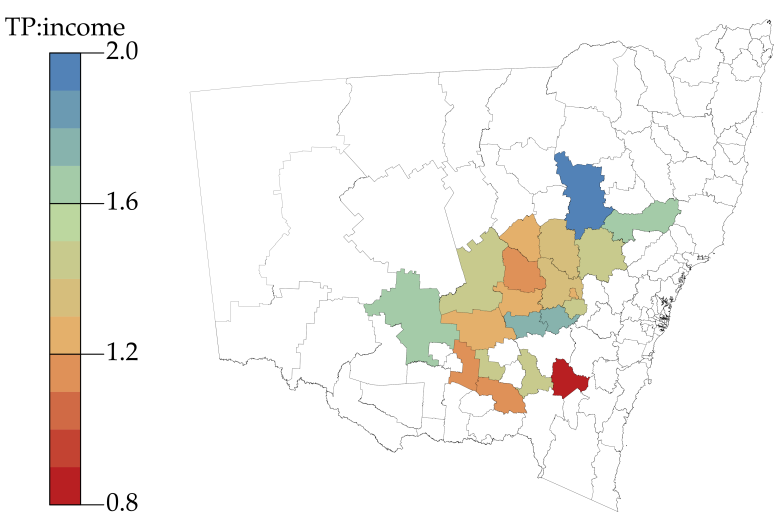

(d) 2015

Figure 9: Ratio between estimated tipping points and mean incomes for WKC conforming local government areas

Table 9: Summary of WKC conforming LGAs

\begin{tabular}{ccccc}
\hline & Num. WKC LGAs & \% of NSW LGAs & \% of NSW population & Avg. tipping point \\
\hline 2012 & 18 & $14.1 \%$ & $3.0 \%$ & $\$ 58,875$ \\
2013 & 19 & $14.8 \%$ & $3.3 \%$ & $\$ 59,345$ \\
2014 & 19 & $14.8 \%$ & $3.0 \%$ & $\$ 57,700$ \\
2015 & 20 & $15.6 \%$ & $4.3 \%$ & $\$ 56,260$ \\
\hline
\end{tabular}




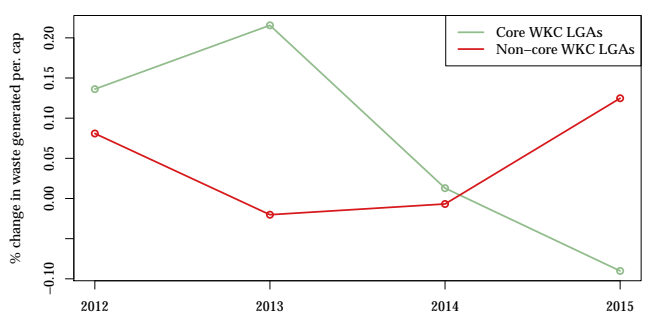

(a) Per-capita waste generation

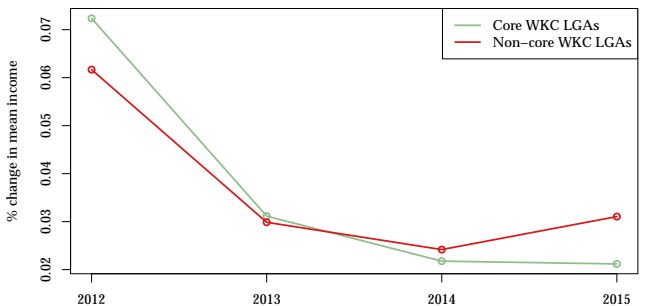

(b) Mean income

Figure 10: Comparison between LGAs conforming to WKC hypothesis for all years of the study and LGAs conforming to WKC hypothesis for at least one year

point estimates also emerged in Mazzanti \& Zoboli (2009), where value added per-capita was used as the economic indicator. Following from Ichinose et al. (2011) and Mazzanti \& Zoboli (2009), such high tipping points occur outside the range of observable mean incomes for most WKC conforming LGAs, indicating a relative decoupling of waste generation and income in NSW generally rather than an absolute decoupling. This is also partly confirmed from the global model results, which indicate a global tipping point above the statewide mean income.

Figure 11 shows the distribution of per-capita waste generation rates, proportion of waste collected as recycling, population density, and mean incomes for WKC and non-WKC conforming LGAs. LGAs conforming to the WKC hypothesis generally exhibit higher per-capita generation rates, and significantly lower proportion of waste collected as recycling. This might suggest that WKC conforming LGAs may in fact have poorer performing waste management systems than non-WKC conforming LGAs. It may be the case that the WKC conforming LGAs have taken steps to improve waste management practices in recent years, which has caused a WKC-type relationship to emerge. However the short time-series dataset used for this study makes confirming this difficult.

The distribution of mean incomes is expected, with non-WKC conforming LGAs including LGAs within the Sydney metropolitan area having a greater level of economic development, and thus higher mean income levels. Considering that mean income is higher, and per-capita generation rates are generally lower in non-WKC LGAs, it may be true that some currently non-WKC conforming LGAs have in fact already experienced a decoupling of waste generation from income. However a longer time-series dataset would be required to confirm this.

Differences in urbanisation, indicated by population density, are found between LGAs conforming to the WKC hypothesis, and those that do not. Mean population density for WKC conforming LGAs is approximately 10 persons $/ \mathrm{km}^{2}$, compared to 865 persons $/ \mathrm{km}^{2}$ for the non-conforming LGAs. This large difference in urbanisation is expected, given that LGAs within the Sydney metropolitan area, the most heavily populated area in Australia, do not exhibit the WKC relationship. The effect of population density on WKC-like behaviour however can only be speculated. Previous studies suggest that population density 


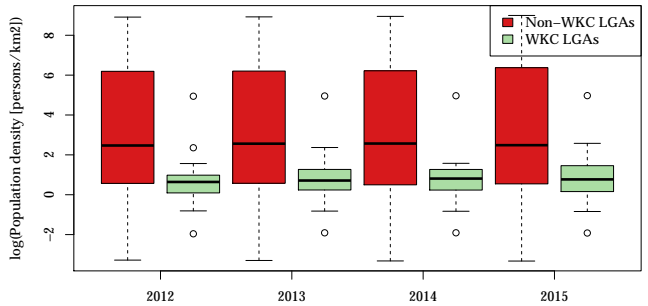

(c) Population density testing a similar WKC.

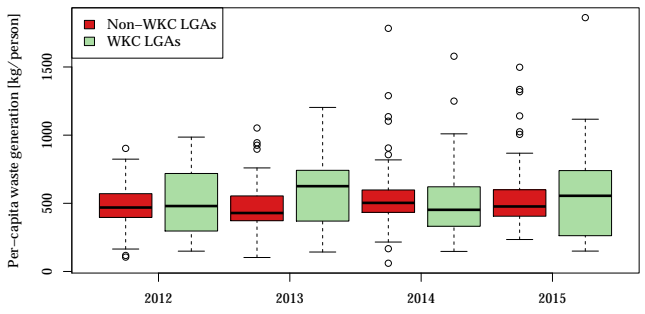

(a) Per-capita waste generation

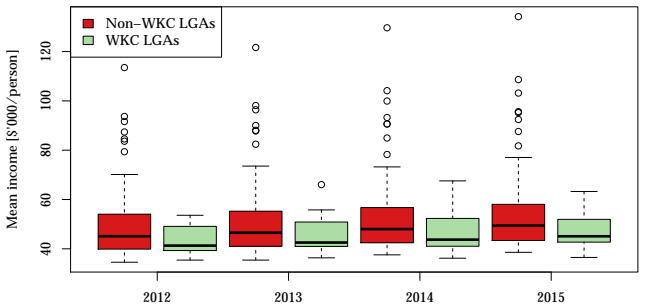

(b) Mean income

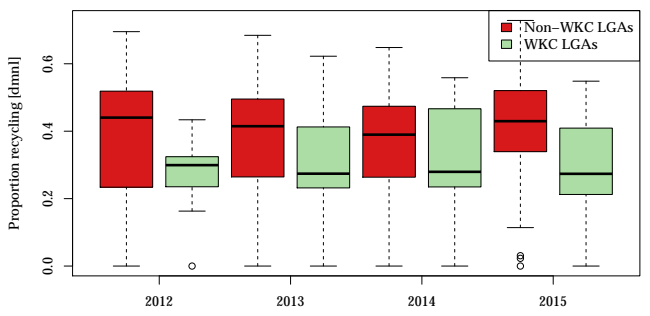

(d) Proportion recycling

Figure 11: Comparison of WKC conforming and non-conforming LGAs

has a positive effect on per-capita generation rates (Mazzanti et al., 2008). Findings from our study show that population density has a mostly negative impact on per-capita generation, which is especially true for WKC conforming LGAs. Reasons for this may be that denser locales have better access to improved waste management and avoidance infrastructure. This finding is consistent with those presented in Jaligot \& Chenal (2018), who found higher levels of population density led to decreased waste generation when

The strength of the divergence between income and per-capita generation for WKC conforming LGAs is measured in Table 10. We compare the percentage difference in per-capita generation rates, and the income elasticity on per-capita generation over the study period for the two sets of LGAs. A Student's $t$-test found no significant difference between distributions for WKC conforming and non-conforming LGAs. This finding might suggest that per-capita rates of waste generation across the non-WKC conforming LGAs are relatively stable and in decline, whereas the WKC-conforming LGAs are in various stages of decoupling, therefore may only recently be experiencing the initial stages of relative decoupling.

Table 10 also compares the mean income elasticity of per-capita generation for each set of LGAs. Mean elasticity for WKC conforming LGAs shows a negative elasticity, providing further evidence of the relative decoupling status for these LGAs. Non-WKC conforming LGAs experience a greater, positive elasticity. Considering the findings from both the global and local models, this is consistent as a general trend in decreasing waste generation and increasing mean income exists across the entire state. In fact, LGAs identified not to be following a WKC trajectory within our study's time frame, may have already experienced 
a decoupling, and are in the final stages of decline with stabilisation. Further investigation on a more complete dataset (i.e., over a longer time period) would be needed to identify the stage of decoupling an LGA in the study might be at, as well to measure the strength of decoupling if it is taking place.

Table 10: Income elasticity of per-capita generation for WKC conforming and non-conforming LGAs

\begin{tabular}{lrrr}
\hline LGA type & Mean $\% \Delta$ PCG & Mean $\% \Delta$ INC & Mean elasticity \\
\hline Non-WKC conforming & $-3.66 \%$ & $3.35 \%$ & 2.19 \\
WKC conforming & $-1.88 \%$ & $3.49 \%$ & -1.56 \\
\hline
\end{tabular}

The results of our study show that there is progress towards the decoupling of per-capita waste generation from mean income across NSW following the WKC hypothesis. While NSW has an agenda for transitioning to the circular economy, with decoupling as a key focus area (NSW Government, 2018), there has been little action towards establishing benchmarks to measure progress towards circular economy objectives. The results of this study give a baseline of decoupling progress at the municipal level following the WKC, and may inform policy through the targeting of specific initiatives towards LGAs not exhibiting decoupling-like behaviour, or for establishing regionally specific decoupling related targets.

\section{Conclusion}

This study has estimated the existence of the WKC across the Australian state of NSW using a GTWR approach, accounting for spatial and temporal heterogeneity in socioeconomic, demographic and structural factors over the 2011 to 2015 period. The GTWR model allowed us to identify specific LGAs within the study area that conform to the WKC hypothesis over time. Our analysis showed that the region to the west of the Sydney metropolitan exhibit the WKC relationship when accounting for spatially varied socioeconomic and structural factors. The ratios of tipping point to mean income for WKC conforming LGAs are between 0.8 and 2, indicating that generally LGAs conforming to the WKC are in stages of relative decoupling rather than absolute.

Findings from the GTWR model show that LGAs conforming to the WKC hypothesis have higher rates of per-capita generation, and lower proportions of waste collected as recycling than non-WKC conforming LGAs in NSW. This suggests that WKC conforming LGAs may have poorer waste management systems, and poorer waste disposal practices than non-WKC conforming LGAs. While it may follow that targeted investment in waste management infrastructure or waste avoidance programs in these regions may drive decoupling, it is unclear from these findings the impact of such strategies in supporting decoupling. The study does not analyse the degree to which LGAs may be decoupling waste generation from household income, however the lower rates of per-capita waste generation suggests that some non-WKC conforming LGAs (namely, those located within the Sydney metropolitan area) may have in-fact already experienced a 
decoupling before the study time period. Additionally, findings show that WKC-conforming LGAs also have lower mean household incomes compared to non-WKC conforming LGAs, however this finding is expected considering mean incomes in the Sydney metropolitan area and other major regional and urban centres tend to have higher mean incomes and greater levels of economic development that regional LGAs.

This analysis demonstrates a new methodology that may be applied in NSW for exploring waste and income decoupling relationships, significant in transitioning to sustainable waste management and the circular economy more broadly. Findings from our study may be used in a strategic policy making context, for example benchmarking and measuring performance against statewide circular economy objectives using the WKC framework might enable appraisal of the effectiveness of circular economy and sustainable waste management policy implementation in driving decoupling. Findings may also inform future policy and/or waste management programs such as waste prevention and initiatives that are tailored to not only current stages of decoupling, but also to locally specific drivers of waste generation.

\section{Bibliography}

Australian Bureau of Statistics (2016). Australian Statistical Geography Standard (ASGS): Volume 3 - Non ABS Structures. Technical Report Australian Bureau of Statistics.

Australian Bureau of Statistics (2017). Australian Statistical Geography Standard (ASGS): Volume 4 - Non ABS Structures. Technical Report Australian Bureau of Statistics.

Australian Bureau of Statistics (2018). Data by Region, 2012-17. Technical Report Australian Bureau of Statistics.

Belsley, D., Kuh, E., \& Welsch, R. (1980). Regression Diagnostics: Identifying Influential Data and Sources of Collinearity. Wiley, New York.

Berrens, R., Bohara, A., Gawande, K., \& Wang, P. (1998). Testing the inverted U hypothesis for US hazardous waste. An application of the generalised gamma model. Economic Letters, 55, 435-440. doi https://doi.org/10.1016/S0165-1765(97) 00088-8

Bivand, R., Pebesma, E., \& Gomez-Rubio, V. (2008). Applied Spatial Data Analysis with R. Springer, New York.

Concu, N. (2000). La tirannia del trade off sconfitta? Turismo, ambiente naturale e rifuti solidi urbani: La ricerca di una EKC Is the tyranny of the trade-off defeated? Tourism, environment, and municipal solid waste: Finding an EKC. Technical Report CRENOS Cagliari, Italy.

Du, Z., Wu, S., Zhang, F., Liu, R., \& Zhou, Y. (2018). Extending geographically and temporally weighted regression to account for both spatiotemporal heterogeneity and seasonal variations in coastal seas. Ecological Informatics, 43, $185-199$. doi https://doi.org/10.1016/j.ecoinf.2017.12.005

Dyson, B., \& Chang, N. (2005). Forecasting municipal solid waste generation in a fast-growing urban region with system dynamics modelling. Waste Management, 57, 669-679. doi https://doi.org/10.1016/j.wasman.2004.10.005

Ellen MacArthur Foundation (2015). Delivering the Circular Economy: a Toolkit for Policymakers. Technical Report.

Ercolano, S., Gaeta, G., Ghinoi, S., \& Silvestri, F. (2018). Kuznets curve in municipal solid waste production: An empirical analysis based on municipal-level panel data from the Lombardy region (Italy). Ecological Indicators, 93, 397-403. doi https: //doi.org/10.1016/j.ecolind.2018.05.021

Fischer-Kowalski, M., \& Amann, C. (2001). Beyond IPAT and Kuznets curves: Globalization as a vital factor in analyzing the environmental impact of
1023/A: 1017560208742 
Fletcher, R., \& Rammelt, C. (2017). Decoupling: a key fantasy of the post-2015 sustainable development agenda. Globalizations, 14, 450-467. doi https://doi.org/10.1080/14747731.2016.1263077

Fotheringham, A., Brundson, C., \& Charlton, M. (2002). Geographically Weighted Regresson: The Analysis of Spatially Varying Relationships. UK: John Wiley and Sons.

Fotheringham, A., Crespo, R., \& Yao, J. (2015). Geographical and temporal weighted regression (GTWR). Geographical Analysis, 47, 431-452. doi https://doi.org/10.1111/gean.12071

Gollini, I., Lu, B., Charlton, M., Brundson, C., \& Harris, P. (2015). GWmodel: An R package for exploring spatial heterogeneity using geographically weighted models. Journal of Statistical Software, 63, 1-50. doi 10.18637/jss.v063.i17.

Goodchild, M. (1992). Geographical information science. International Journal of Geographical Information Systems, 6, 31-45.

Goovaerts, P. (1997). Geostatistics for Natural Resources Evaluation. Oxford University Press, New York.

Huang, B., Wu, B., \& Barry, M. (2010). Geographically and temporally weighted regression for modeling spatio-temporal n variation in house prices. International Journal of Geographical Information Science, 24, 383-401. doi:https://doi.org/ $10.1080 / 13658810802672469$

Ichinose, D., Yamamoto, M., \& Yoshida, Y. (2011). GRIPS Discussion Paper 11-0\%: The decoupling of affluence and waste discharge under spatial correlation: do richer communities discharge more waste?. Technical Report National Graduate Institute for Policy Studies.

Jackson, T. (2009). Prosperity Without Growth: Economics for a Finite Planet. Taylor and Francis Ltd, Washington DC, USA.

Jaligot, R., \& Chenal, J. (2018). Decoupling municipal solid waste generation and economic growth in the canton of Vaud,

Switzerland. Resources, Conservation and Recycling, 130, 260-266. doi/https://doi.org/10.1016/j.resconrec.2017.12. 014

Kannangara, M., Dua, R., Ahmadi, L., \& Bensebaa, F. (2018). Modeling and prediction of regional municipal solid waste generation and diversion in Canada using machine learning approaches. Waste Management, 74, 3-15. doi https://doi. org/10.1016/j.wasman.2017.11.057

Keser, S., Duzgun, S., \& Aksoy, A. (2012). Application of spatial and non-spatial data analysis in determination of the factors n that impact municipal solid waste generation rates in Turkey. Waste Management, 32, 359-371. doi 10.1016/j.wasman. 2011.10 .017

Khan, D., Kumar, A., \& Samadder, S. (2016). Impact of socioeconomic status on municipal solid waste generation rate. Waste Management, 49, 15-25. doi 10.1016/j.wasman.2016.01.019

Kim, Y., Tanaka, K., \& Ge, C. (2018). Estimating the provincial environmental Kuznets curve in China: a geographically weighted regression approach. Stochastic Environmental Research and Risk Assessment, 32, 2147-2163. doi https://doi. org/10.1007/s00477-017-1503-z.

Kirchherr, J., Reike, D., \& Hekkert, M. (2017). Conceptualizing the circular economy: An analysis of 114 definitions. Resources, Conservation and Recycling, 127, 221-232. doi https://doi.org/10.1016/j.resconrec.2017.09.005.

Kolekar, K., Hazra, T., \& Chakrabarty, S. (2016). A review on prediction of municipal solid waste generation models. Procedia Environmental Sciences, 35, 238-244. doi https://doi.org/10.1016/j.proenv.2016.07.087

Kumar, A., \& Samadder, S. (2017). An empirical model for prediction of household solid waste generation rate - A case study of Dhanbad, India. Waste Management, 68, 3-15. doi https://doi.org/10.1016/j.wasman.2017.07.034

Kuznets, S. (1955). Economic growth and income inequality. American Economics Review, 45, 1-28.

Lebersorger, S., \& Beigl, P. (2011). Municipal solid waste generation in municipalities: quantifying impacts of household

n structure, commercial waste and domestic fuel. Waste Management, 9-10, 1907-1915. doi https://doi.org/10.1016/j. wasman.2011.05.016.

Lewandowska-Gwarda, K. (2018). Geographically weighted regression in the analysis of unemployment in Poland. International 
Journal of Geo-Information, 7, 1-16. doi https://doi.org/10.3390/ijgi7010017

Ma, X., Zhang, J., Ding, C., \& Wang, Y. (2018). A geographically and temporally weighted regression model to explore the spatiotemporal influence of built environment on transit ridership. Computers, Environment and Urban Systems, 70, 113-124. doi https://doi.org/10.1016/j.compenvurbsys.2018.03.001

Maddison, D. (2006). Environmental Kuznets curves: A spatial econometric approach. Journal of Environmental Economics and Management, 51, 218-230. doi https://doi.org/10.1016/j.jeem.2005.07.002

Mazzanti, M., Montini, A., \& Zoboli, R. (2008). Municipal waste generation and socioeconomic drivers - evidence from comparing northern and southern Italy. The Journal of Environment and Development, 17, 51-69. doi:https://doi.org/ $10.1177 / 1070496507312575$

Mazzanti, M., \& Nicolli, A. (2012). Waste dynamics in economic and policy transitions: decoupling, convergence and spatial

] effects. Journal of Environmental Planning and Management, 55, 563-581. doi https://doi.org/10.1080/09640568.2011. 616582

Mazzanti, M., \& Zoboli, R. (2009). Municipal waste Kuznets curves: evidence on socio-economic drivers and policy effectiveness from the EU. Environmental Resource Economics, 44, 203-230. doi/https://doi.org/10.1007/s10640-009-9280-x

Montello, D., \& Sutton, P. (2012). An introduction to scientific research methods in geography and environmental studies. London: Sage.

Montevecchi, F. (2016). Policy mixes to achieve absolute decoupling: a case study of municipal waste management. Sustainability, 8, 442-464. doi doi:10.3390/su8050442

NSW EPA (2016). NSW Local Government Waste and Resource Recovery Data Report 2014-15. Technical Report New South Wales Environment Protection Authority.

NSW Government (2018). NSW Circular Economy Policy Statement: Too good to waste. Technical Report NSW Government.

OECD (2018). OECD Global Material Resources Outlook to 2060 - Economic Drivers and Environmental Consequences. Technical Report OECD Publishing, Paris.

Oribe-Garcia, I., Kamara-Esteban, O., Martin, C., Macarulla-Arenaza, A., \& Alonso-Vicario, A. (2015). Identification of influencing municipal characteristics regarding household waste generation and their forecasting ability in Biscay. Waste Management, 39, 26-34. doi 10.1016/j.wasman.2015.02.017

Suárez-Eiroa, B., Fernández, E., Méndez-Martínez, G., \& Soto-Oñate, D. (2019). Operational principles of circular economy 口 for sustainable development: Linking theory and practice. Journal of Cleaner Production, 214, 952-961. doi https://doi. org/10.1016/j·jclepro.2018.12.271

Sun, N., \& Chungpaibulpatana, S. (2017). Development of an appropriate model for forecasting municipal solid waste generation in Bangkok. Energy Procedia, 138, 907-912. doi https://doi.org/10.1016/j.egypro.2017.10.134

Trang, P., Dong, H., Toan, D., Hanh, N., \& Thu, N. (2017). The effects of socio-economic factors on household solid waste generation and composition: A case study in Thu Dau Mot, Vietnam. Energy Procedia, 107, 253-258. doi https://doi. org/10.1016/j.egypro.2016.12.144

Wang, P., Bohara, A., Berrens, R., \& Gawande, K. (1998). A risk based environmental Kuznets curve for US hazardous waste sites. Applied Economics Letters, 5, 761-763. doi https://doi.org/10.1080/135048598353970

Ward, J., Sutton, P., Werner, A., Constanza, R., Mohr, S., \& Simmons, C. (2016). Is decoupling GDP growth from environmental impact possible? PLoS ONE, 11. doi/https://doi.org/10.1371/journal.pone.0164733

Wiedmann, T., Schandl, H., Lenzen, M., Moran, D., Suh, S., West, J., \& Kanemoto, K. (2016). The material footprint of 口 nations - reassessing resource productivity. Proceedings of the National Academy of Sciences, 112, 6271-6276. doi http: //dx.doi.org/10.1073/pnas.1220362110

World Trade Organization (2017). 18 July 2017 Committee on Technical Barriers to Trade. Technical Report World Trade Organization. 


\section{Appendix A. Variation in $\beta$ coefficient and $t$-value estimates for values of $\lambda$}

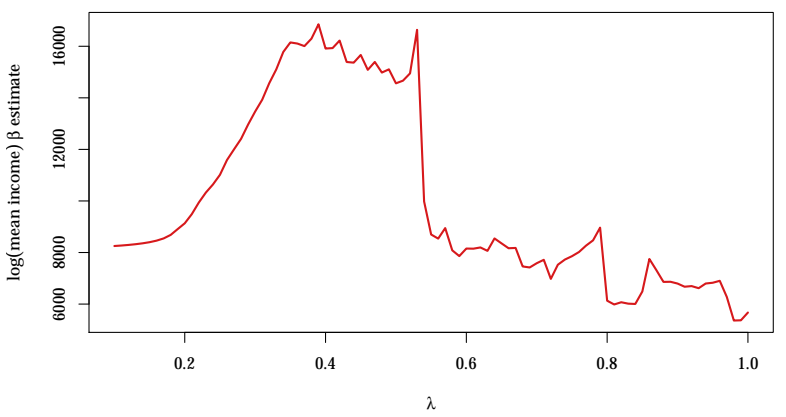

(a)

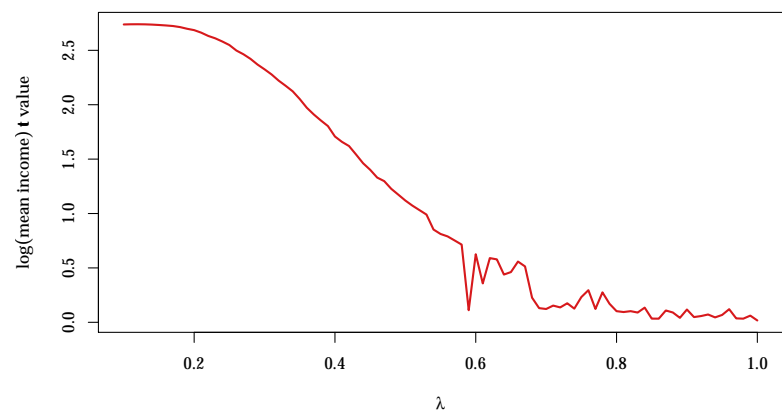

(c)

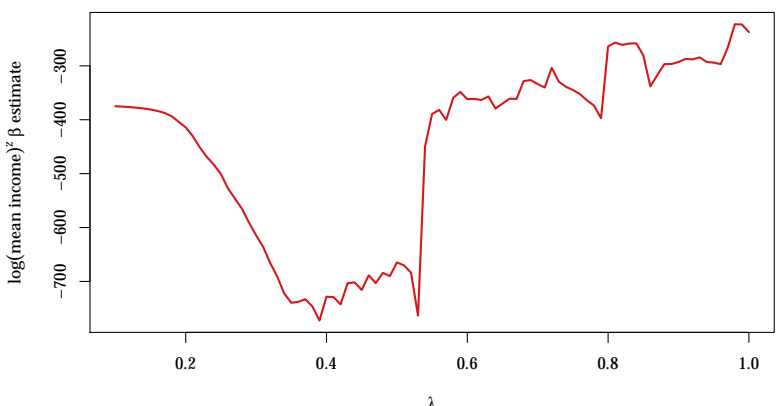

(b)

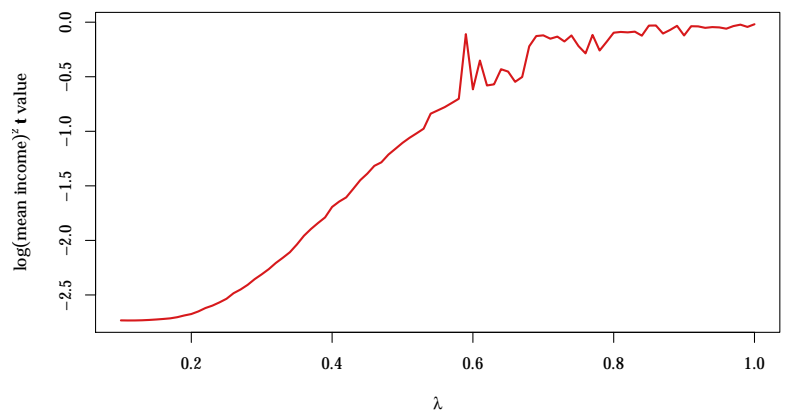

(d)

Figure A1: Variation in $\beta$ coefficient and $t$-value estimates for values of $\lambda$. (a) and (b) are the $\beta$ estimates for the log(mean income) and $\log (\text { mean income })^{2}$ variables and (c) and (d) are $t$-value estimates 